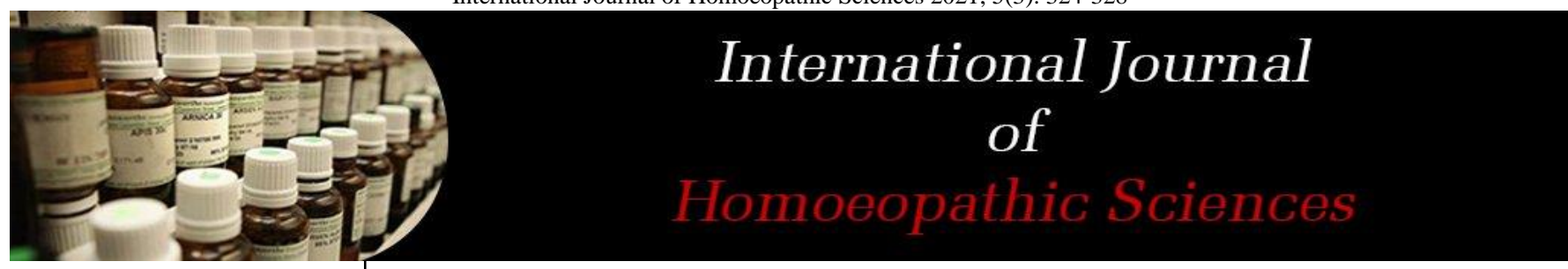

E-ISSN: 2616-4493 P-ISSN: 2616-4485 www.homoeopathicjournal.com IJHS 2021; 5(3): 324-328 Received: 23-05-2021 Accepted: 25-06-2021

Dr. Saurav Rathore Associate Professor \& HOD, Department of Surgery, Government Homoeopathic Medical College \& Hospital, Paraspani, Godda, Jharkhand, India
Corresponding Author: Dr. Saurav Rathore Associate Professor \& HOD, Department of Surgery, Government Homoeopathic Medical College \& Hospital, Paraspani, Godda, Jharkhand, India

\section{Homoeopathic management in molluscum contagiosum}

\section{Dr. Saurav Rathore}

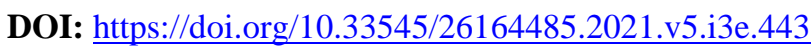

Abstract

Homoeopathy has been acclaimed for the treatment of Molluscum Contagiosum. The treatment is targeted towards the root of the illness and hence homeopathy brings about lasting cure rather than temporary relief. The lesion is small, usually asymptomatic, caused by a DNA virus of the pox group. It is more common and extensive in people with atopic eczema especially associated with asthma or hay fever; people whose immunity is suppressed because of recurrent infections or immunosuppressant diseases like HIV- AIDS and those who are on corticosteroid treatment for a long time. The homoeopathic treatment are prescribed on the basis of the chief complaint as well as on the basis of an in-depth study of the entire constitution of an individual, it only helps in getting rid of the existing molluscum contagiosum but it also helps in removing the tendency for this condition to recur.

Keywords: Homoeopathic treatment, molluscum contagiosum, repertory, viral infection, constitutional medicine. Sycotic miasm

\section{Introduction}

\section{Definition}

Molluscum Contagiosum is a common cutaneous viral infection in children. It is caused by infection with a DNA virus of the Mollusci poxvirus genus. The word Molluscum contagiosum comes from the Latin word named MOLLUSCUS means SOFT characterized by pea sized semi-globular pearl like lesion with minute central depression.

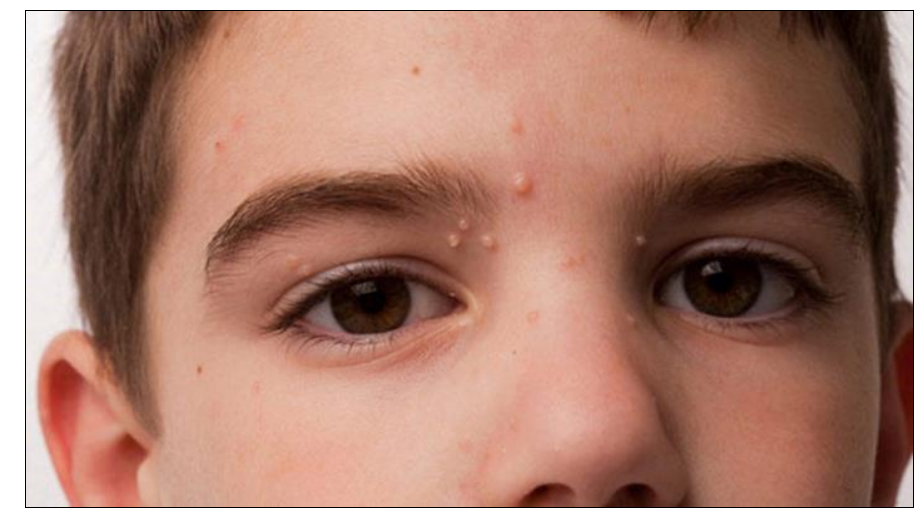

Aetiopathogenesis

Molluscum Contagiosum is caused due to Exciting cause and categorized under individual acute disease. In this molluscum contagiosum virus acts as an exciting cause. Large numbers of MCV particles can be extruded from skin lesions, and large amounts of viral DNA can readily be extracted from virions. MCV has not been grown in established cell cultures, but virus from skin lesions has been propagated in human foreskin xenografts. The recognition of MCV transcriptional control elements in genetically engineered vaccinia virus indicates that MCV has a replication strategy similar to other poxviruses.

\section{Epidemiology}

MCV infection occurs worldwide and appear specific to humans. Virus occurs throughout the world, most commonly causing disease in childhood. 
Type $1 \mathrm{MCV}$ is found in the majority of infections (76$97 \%$ ), and whilst there is no relationship between virus type and lesional morphology or anatomical distribution. The disease is common, but its incidence in most areas is not reliably known. It commonly affects children and sexually active adults as well as immune- compromised individuals. The disease is endemic with a higher incidence within institutions and communities where there is overcrowding, poor hygiene, and poverty.

The incidence of disease is $2 \%$ to $8 \%$ in some populations and is more common among 10 to 12 year-old children in developed countries than in developing countries, such as Fiji and the DRC, where the peak incidence is reported between ages 2 and 3 years and 1 and 4 years, respectively. In New Guinea, a prevalence of $22 \%$ with an incidence of $6 \%$ in children younger than 10 years of age has been reported. The disease occurs sporadically, although it can become endemic, particularly in institutions such as children's day care or boarding schools, or in communities with poor hygiene and overcrowding. Contact transmission has occurred nosocomially, by tattooing, wrestling, or by swim team members sharing towels. Abundant lesions are common in atopic individuals who may acquire a patchy and irritable eczema around sites of infection known as eczema molluscatum. Genital molluscum sometimes coincides with other sexually acquired diseases, including AIDS, and may signal sexual abuse of a child; otherwise, children may acquire lesions on the arms, or most often, the upper torso.

\section{Clinical features}

1. The typical lesion of molluscum contagiosum are discrete, dome shaped, umbilicated waxy papules.

2. They may be skin coloured, pink or white.

3. A small central punctum frequently is visible.

4. If lesions are squeezed between the fingers, a cheesy or sebaceous-looking matter release from the hilum.

5. A lesion starts as a tiny papule and progresses to a size of $5-10 \mathrm{~mm}$ in $6-12$ weeks.

6. Lesion may appear vesicular because of a translucent quality.

7. The size may vary from 1 to $5 \mathrm{~mm}$, few lesions can occur as large as 10 to $15 \mathrm{~mm}$ called as giant molluscum or molluscum contagiosum giganteum.

8. Usually there is no itching or tenderness and no generalized symptoms.

9. Lesions can occur anywhere on the body, but mostly on face, eyelids, neck, chest, axillae, sides of trunk, fold areas of extremities, and genitalia in children. Palms and soles are rarely involved.

10. After trauma, or spontaneously after several months, inflammatory changes result in suppuration, crusting and eventual destruction of the lesion.

11. The disease usually lasts for 6 to 9 months but occasionally persisting for as long as 4 years. Although individual lesions persist for only about 2 months.

12. Lesions usually resolute spontaneously by forming erythema, pus and crusting.

13. Eczematous dermatitis occurs around the molluscum in $10 \%$ of cases known as molluscum dermatitis.

14. In patient with chronic eczema or even atopic eczema, especially in areas of skin treated with glucocorticoids (local immune deficiency), hundreds of these mollusca contagiosa may develop: eczema molluscum.

\section{Diagnosis}

1. The diagnosis of molluscum contagiosum is usually established on the basis of clinical appearance alone.

2. Smears, made from the cheesy material expressed from the lesion is crushed between two slides and stained with Giemsa and Wright's stain show homogenous pear-shaped molluscum bodies.

3. Skin biopsy reveals Henderson-Paterson bodies, which occasionally is used for large or atypical lesions.

4. The distinctive umbilication can be seen more easily with a dermatoscope or after freezing.

5. Demonstrating poxvirions by electron microscopy.

\section{Treatment}

Contemporary treatments for MC include cryotherapy, curettage, and topical application of caustic agents. Commonly chosen treatment method of MC is "wait and see," which usually resolves spontaneously after several months to years, but it is the great source of embarrassment, often limiting social activity. Therapy becomes obligatory, because children may scratch the lesions and infection may spread to other parts or to other people. Curettage is associated with a high risk of relapse, scarring and most frightening to children if performed repeatedly, owing to pain and fear.

\section{Homoeopathic approach}

Homoeopathy has wide scope in the treatment of Molluscum Contagiosum. The treatment is targeted towards the root of the illness and hence homoeopathy brings about lasting cure rather than temporary relief. The Homoeopathic treatment that is given is referred to as Constitutional Treatment. This means that the medicines are prescribed on the basis of the chief complaint as well as on the basis of an in-depth study of the entire constitution of an individual. This includes the study of a person's nature of complaints, his likes and dislikes about food, his personality and mental attributes as well as his past and family history. When all these criteria are taken into account for deciding the patient's remedy, the chosen drug is called as Constitutional remedy and it helps to heal the disease from its roots.

To the homeopath, disease is an imbalance which affects the whole person, first his or her vitality is affected, perhaps as a result of exponent's poor weather, lack of sleep, continuous stress or a variety of other factors, when this persists, the symptoms "localize" in specific areas such as tonsils, neck muscles, stomach, etc. This localization is usually considered to be the disease. Any agent which by virtue of some inherent quality can affect the life principle in such a way as to produce disagreeable sensations and functions may be termed as a 'morbific agent'. A morbific agent is a concrete reality, and quality is an abstraction. Thus disease is produced qualitatively, cure is affected qualitatively and the process by which these are brought about is called by the name of "dynamic processes". The biological concept of disease as elaborated above accepted in homeopathy. In the study of disease, however, the homeopathic physician considers the individual response as of greater importance from the standpoint of the selection of the remedy and is guided by the totality of symptoms. Has interest in morbific agents, therefore, is strictly limited to the help he obtains from their study arriving at the diagnosis.

Homoeopathic treatment not only helps in getting rid of the 
existing Molluscum Contagiosum but it also helps in removing the tendency for this condition to recur. Also the method of healing of the molluscum is without the use of any surgical aids and hence it helps in preventing scarring and other such side-effects that can occur due to surgery. Molluscum is predominantly Sycotic disease. So it requires an Anti-sycotic medicine to cure the case. In most cases the lesion disappears even without any treatment in a couple of months. However some lesions may persist for some time and require intervention.

\section{Homoeopathic therapeutics}

Some homeopathic medicines found to be efficacious in cases of Molluscum contagiosum are,

\section{Belladonna}

Fine complexion and delicate skin; dryness; bright redness; burning heat; throbbing pains; pains appear and disappear suddenly; wildly delirious, restless, sensitive, nervous; child jovial and entertaining when well but violent when sick.

- Red, inflamed molluscum.

- Burning of the skin, also felt by the hand and it continues to burn after touching the skin, as though a hot stove has been touched, very characteristic.

- Red, hot and shining redness of the skin, with dryness, and swelling of the parts.

\section{Bromium}

Hot patient; fatty, fair; great weakness and easily overheated then sweat profusely sensitive to drafts; glandular affinity; tremulous; better by eating; quarrelsome and/or friendly, cheerful and fairly happy.

- Molluscum commonly appear on face, arms and shoulders.

- Sensation of something being alive in the skin.

- Worse warmth or warm, damp weather.

\section{Calcarea Arsenicum}

Chilly patient; anemic; tendency for epilepsy and nephritic conditions; infantile hepato-splenomegaly; restless, anxious and emotional child; dreads to be alone.

Pearly eruptions. Vesicular, small and shiny in appearance.

\section{Calcarea Carbonica}

Calcarea carbonica is an effective medicine for treating the molluscum contagiosum.

These children are typically soft, over-fat, fair, chilly, and lethargic. Children with red face, flabby muscles, who sweat easily and take cold readily in consequence. Large heads and abdomens; fontanelles and sutures open; bones soft, develop very slowly. Curvature of bones, especially spine and long bones; extremities crooked, deformed; bone irregularly developed. Head sweats profusely while sleeping, wetting pillow far around. Profuse perspiration, mostly on back of head and neck, or chest and upper part of body. Difficult and delayed dentition with characteristic head sweats, and open fontanelles. During either sickness or convalescence, great longing for eggs; craves indigestible things; aversion to meat. Obstinacy; slight mental effort produces hot head. Averse to work or exertion. Apprehensive; Forgetful, confused, low-spirited. Warts on face and hands.

\section{Carcinosinum}

Carcinosinum is indicated if the mental and emotional symptoms indicate it. Nevertheless, some physical signs are often seen in this remedy: the Molluscum contagiosum.

\section{Causticum}

These are people who live with the feeling that they have a Damoclean sword hanging above their head. There has been a dramatic incident in their lives. For example, after a very difficult labor and birth, the infant is fearful, whimpering, and cries when others cry (out of compassion, since misfortune has befallen them). Indeed, these children live in constant fear that new worries will materialize. They cannot go to bed alone at night, they fear the dark, and are often afraid of dogs. We often observe weakness of some kind.

Frequently, warts will be present, often small, widely scattered warts of the molluscum contagiosum type, or larger warts near the edge of the fingernails.

\section{Dulcamara}

Chilly patient, with skin affections brought on or worse by exposure to cold, damp, rainy weather; restless and irritable.

- Ailments after taking bath in swimming pool.

- Humid eruptions on face, genitals, hands etc.

- Flat, pearly eruptions.

- Worse cold in general, damp, rainy weather

\section{Medorrhinum}

Here is a key constitutional remedy for the "sycotic" terrain denoted by Hahnemann. These individuals have a problem with time. They are constantly projecting into the future. "What comes next?" This question, which is constantly on their lips, ruins the present for them.

In the family history there are cases of cancer and chronic rheumatism. Medorrhinum infants sleep flat on their stomach, rear in the air. They often have a red rash (erythema) on the buttocks. The children are sensitive to humidity. Their legs are constantly in motion while they are seated.

In the eyes, we find chronic conjunctivitis, with the lids stuck together in the mornings, and astigmatism.

Amelioration at the seaside is a good symptom of this remedy. On the skin, we find a large number of small molluscum pendulum around the neck. "Time is money." Medorrhinum tries to control time. These individuals are constantly projecting their minds into the future, making them clairvoyant, which makes this a remedy for mediums who predict the future. On the other hand, lack of control, or anarchy, leads to skin tumors and cancer.

\section{Natrum Muraticum}

Great emaciation; loosing flesh while living well; throat and neck of child emaciate rapidly during summer complaint. Great liability to take cold. Irritability: child cross when spoken to; crying from slightest cause; gets into a passion about trifles, especially when consoled with. Children slow in learning to walk. Child will be slow in learning to speak. Small and underweight child. Warts on palms of hands.

\section{Silicea}

Umbilicated eruptions with offensive pus. Itching only in daytime and evening. Extremely chilly patient; profuse, offensive discharges; glandular affinity; large head and distended abdomen, weak ankles; open fontanelles and sutures; slow in learning to walk; constipation, stool being partly expelled recedes back again; all symptoms worse by cold except stomach complaints; children are obstinate, head strong, cry when spoken kindly to, nervous, apprehensive, oversensitive, irritable and fearful. 
- Tuberous spots on skin of light red color.

- Eruptions heal with difficulty and suppurate easily.

\section{Sulphur}

Molluscum in a child; body and limbs covered with soft, round, smooth, apparently painless tumours with broad base. At first of the colour of the skin, then assuming a bluish, and finally a purple or pinkish hue; found on puncture to contain a semi-fluid, sebaceous matter. These tumours vary in size from that of a large bean to a filbert, and were found in all stages of development at the same time, about eighty in number. After Sulphur, no new tumours formed, and the old shrivelled up, without discharging.

\section{Thuja occidentalis}

It is a remedy for molluscum for Chilly patient; dark, fleshy children with greasy face; dark hair and unhealthy Skin, looks dirty with brownish spots; perspiration on uncovered parts, smells sweetish and strong; complaints worse damp, humid weather; lazy.

- Eruptions only on covered parts

- Umbilical form of eruptions

In elderly children, we obtain history of nightmares, dreams of falling and someone chasing and startling in sleep. Here too thuja works very well. The remedy works from within outwards. The eruptions become big and they burst open and then subside.

\section{Tuberculinum}

It has a good role in establishing cure if given as intercurrent.

\section{Repertorial appoarch}

- Boericke W - Pocket manual of homoeopathic materia medica with Indian medicine and repertory Chapter: SKIN

Rubric: MOLLUSCUM

Remedies: Brom.; Bry.; Calc. ars.; Calc. C.; kali. iod.; Lyc.; Merc. S.; Nat. m.; Sil.; Sul.; Teucr.

\section{- Murphy R - Homoeopathic medical repertory}

Chapter: Diseases

Rubric: MOLLUSCUM contagiosum

Remedies: Brom. bry. calc. Calc-ar. kali-i. lyc. merc. merc-sul. Nat-m., Sil. sulph. teucr. Thuj.

- Clarke J H - A clinical repertory to the dictionary of materia medica

Chapter: Clinical

Rubric: Molluscum

Remedy: Sul.

Subrubric: Molluscum Contagiosum

Remedies: Calc., Sil.

\section{- Van zandvoort R - Complete Repertory}

Chapter: SKIN

Rubric: ERUPTIONS

Subrubric: molluscum

Remedies: brom. bry. calc. calc-ar. kali-i. lyc. merc. nat-m. sil. sulfa. sulph. teucr. thuj.

Sub-subrubric: contagiosum; molluscum

Remedies: BROM. bry. calc. CALC-AR. carc. germmet. jug-c. kali-i. lepr. lyc. merc. nat-m. sacch-a. sil.

\section{SULPH. teucr. THUJ.}

- Lilienthal S - Homoeopathic therapeutics Chapter: MOLLUSCUM

Remedies: Kali iod., Lyc., Sil., Thuj

- Schroyens F - Synthesis Repertorium Homeopathicum Syntheticum. 9.1

Chapter: SKIN

Rubric: ERUPTIONS

Subrubric: molluscum

Remedies: Brom. bry. calc. Calc-ar. kali-i. lyc. merc-scy. nat-m. Sil. sulph. teucr. vac.

Sub-subrubric: contagiosum; molluscum

Remedies: calc. carc. kali-i. lyc. sil. sulf. thuj.

- Tiwari S K - Homoeopathy child care therapeutics, child types, repertory

Rubric: MOLLUSCUM CONTAGIOSUM

Remedies: Ambr, ARS, calc, calc-p, caust, con, dulc, graph, hep, kali-i, lyc, MERC, NAT-M, nit-ac, phos-ac, phos, PULS, rhus-t, SIL, staph, SULPH, thuj.

- Van zandvoort $\mathbf{R}$ - Repertorium universale III Chapter: SKIN

Rubric: PHENOMENA

Subrubric: ERUPTIONS

Sub-sub-rubric: molluscum

Remedies: brom. bry. calc. calc-ar. germ-met. kali-i. lyc. merc. nat-m. sil. sulfa. sulph. teucr. thuj.

Sub-sub-sub-rubric: contagiosum

Remedies: BROM. bry. calc. CALC-AR. carc. germmet. jug-c. kali-i. lepr. lyc. merc. nat-m. sacch-a. sil. SULPH. teucr. THUJ.

\author{
Abbreviations \\ (MCV) Molluscum Contagiosum Virus, (HIV) Human \\ immunodeficiency virus, (AIDS) Acquired Immuno- \\ deficiency syndrome, (DRC) Democratic Republic of the \\ Congo
}

\section{Conclusion}

Molluscum Contagiosum is a common cutaneous viral infection in children. It is caused by infection with a DNA virus of the Molluscipoxvirus genus. It is a benign but none the less frequently troublesome viral infection that generally affects young children. The typical lesion of Molluscum Contagiosum are discrete, dome shaped, umbilicated waxy papules. They may be skin coloured, pink or white. A small central punctum frequently is visible. Usually there is no itching or tenderness and no generalized symptoms. Lesions can occur anywhere on the body, but mostly on face, eyelids, neck, chest, axillae, sides of trunk, fold areas of extremities, and genitalia in children.

This study has been conducted on the patient's with Molluscum Contagiosum disease to assess the effectiveness of constitutional approach in the treatment of Molluscum Contagiosum and to analyze group of remedies effective in the treatment of Molluscum Contagiosum in pediatric age group.

For making a homoeopathic totality of symptoms the mental symptoms are very important. The mind is the most crucial level for the human being. The mind of a person is the true essence of individual. So understanding the mind of the 
patient clearly is very important.

\section{References}

1. Burns T, Breathnach S, Cox N, Griffiths C. Editors. Rook's textbook of dermatology. 8th ed. Chichester, West Sussex, UK: Blackwell Publishing Ltd 2, 33, 112.

2. Falco OB, Plewig G, Wolff HH, Winkelmann editors. Dermatology. New York, UAS: Springer - Verlag Berlin Heidelberg 1991, 21-2.

3. Fields BN, Knipe DM, Howley MD. Editors. Fields virology. 4th ed. USA: Lippincott Williams \& Wilkins Publishers 2001;2:90.

4. Fisher CE. A hand book on the diseases of children and their Homoeopathic reatment. New Delhi, India: B. Jain Publishers (P) Ltd 2004, 753.

5. Gupta R, Manchanda RK. Text book of dermatology for homoeopaths. New Delhi, India: B. Jain Publishers (P) Ltd 2005, 90-1.

6. Banerjea S. Miasmatic prescribing - Its philosophy, diagnostic classifications, clinical tips, miasmatic repertory, miasmatic weightage of medicines and case illustrations. 2nd ed. New Delhi, India: B. Jain Publishers (P) Ltd 2010, 231.

7. URL:http://www.homeorizon.com/homeopathicarticles/dermatology/molluscum-warts-cure. Dated: March 16, 2014.

8. URL:http://dermind.tripod.com/mc.htm. Dated: March 16, 2014.

9. Douglas MB. Children's types. New Delhi, India: Indian Books \& Periodicals Publishers 2008;3:20.

10. Bolongnia JL, Jorizzo JL, Rapini RP editors. Dermatology. 2nd ed. UK: Mosby Elsevier, An imprint of Elsevier limited 2008;1:1229-32.

11. Dearborn FM. Diseases of the skin including the exanthemata - For the use of General Practitioners and Advanced students. New Delhi, India: B. Jain Publishers (P) Ltd 2006, 3-7, 12-3, 323.

12. Douglass ME. Skin diseases- Their description, Etiology, Diagnosis and Treatment according to the Law of Similars. New Delhi, India: B. Jain Publishers (P) Ltd 2006, 426-7.

13. English JSC. General dermatology - An Atlas of Diagnosis and Management. UK: Clinical Publishing An imprint of Atlas Medical Publishing Ltd 2007, 120. 